\title{
Overview of University Sport in Iran
}

\author{
Hamidreza Mirsafian, Azadeh Mohamadinejad
}

Semmelweis University, Faculty of Sport and Physical Education Sciences, Budapest, Hungary

ABSTRACT

This article focuses on the structure and management systems of sport at Iranian universities. The method of this research was through an analysis of documents. Sport in the system of Iranian universities is divided into three different categories. The physical education department of the Ministry of Science, Research and Technology of Iran is responsible for sport at universities in the country, and managing sport affairs. Authority was granted to secretariats in the various regions so that decision making would be decentralized due to the large size of the country and the large number of universities in the various geographical regions. Due to this great geographical diversity, universities should continue their activities under the supervision of sport secretariats in their given regions. The participation of students in sport activities at Iranian universities was calculated in three categories; students with different interests and skills can participate in various numbers of sports, championships, and sport festivals. At this time, with regards to the scientific attitudes towards sport and physical activities and the expanding culture of sport at Iranian universities, the number of participants in sport activities is increasing. In the conclusion it is stated that improving the knowledge and attention of students regarding the importance of sport in different aspects of education and life, as well as the recognition of present barriers and support of campus volunteers, could help to increase the participation of students in sport activities. Moreover, the allocation of more power and authority to each region, as well as holding different local and traditional sport festivals, could help to improve the development of sport at Iranian universities.

KEYWORDS Physical Education, management, university student, Iran

\section{Introduction}

One of the human needs for life is regular physical activity - it is vital for health and well-being. Banning humans from physical activity might not only cause depression, but it also might cause a lack of proper performance and physical ability. The human's need for activity during the history of life is always associated with discovering new ways of developing bodily abilities. Physical education and sport in the history of human life in many ways is manifest (Razi 2007). Among all of the countries all around the world Iran was the first country to place special focus on sport and physical education in its teaching and training disciplines. Iran found the importance of body well-being and power in establishing a brave army. A book by one of the most famous Iranian historians quotes Herodotus, the famous fifth-century B.C. Greek historian, who stated: Iranians from five to twenty years learn these subjects:

\footnotetext{
-horse driving,

-archery,
} 
-honesty.

In those times, Iranians, for teaching and training the youth, in addition to learning many kinds of sports, tried to understand theoretical education ( $\operatorname{Rad}$ et al. 2006).

At present, sport in Iran is also taught in various ways at all different educational levels. One of the main and most efficient centers of development and education of sports is universities, which consider sport in different practical and scientific ways (Shajie et al. 2007). Physical education (PE) and sport is one of the special pillars at the universities, aimed at developing physical and mental health, expanding the sports culture among young people, and helping to improve the health culture in the society. One of the aims of sport at universities is to encourage students to participate in sport and to have an active lifestyle, which not only helps to improve their physical and mental health, but also helps them achieve better academic levels at universities. Regarding the fact that the future of society will be in the hands of these persons - the future managers and administrators of the country developing their physical and mental health could obviously contribute to a better community (Khorami 2009). This article aims to present an overview of the structure and the management systems of Iranian university sport.

\section{Structure of university sport in Iran}

In this chapter the structure of sport at Iranian universities is discussed on the basis of three levels.

\subsection{Local level: PE and sport departments}

PE departments at Iranian universities are responsible for all of the sport affairs in two different parts, recreation and competition. The organizational chart of this department consists of the head of the department, vice dean, several sports experts who have different responsibilities, such as sport recreation, sport events, university festivals, sport competition, and women's sports affairs. Based on student interest, several sport classes are held at universities throughout the academic year. At the weekends, different recreational activity programs, such as mountaineering, camping, and hiking in nature, are also programmed by this department.

In addition, various sport matches and competitions in the form of different sport festivals are held at the universities.

\subsection{Regional level: regional secretariats}

The universities in each region are covered by the secretariat of sport affairs related to that region. The responsibilities and duties of the region's secretariats will be discussed in this article.

Every few years, one university in each region of the country (based on facilities, staff, budgets, etc.) is nominated to be the secretariat of all universities in that region.

\subsection{National Level: National University Sport Federation of Iran (N.U.S.F.IRAN)}

One of the main organizations that has a close relationship with FISU and is responsible for implementing the objectives and rules within Iran is the National I.R.Iran University Sports Federation, which is considered to be one of Iran Amateur Sports Federations. It is a public, nongovernmental institute having legal entity and is considered the highest competent authority in universities and higher education institutes of sport and was established for the promotion and integration of universities and higher educational institutes, based on Iranian rules and regulations and the principles and rules of FISU, issued through the permission of the Iran Ministry of Science, Research and Technology" (National Iranian University Sport Federation 2011).

Physical recreation and sport activities are one of the most important parts of sport in universities, playing a special role in achieving the aforementioned goals. In this review, we plan to 
consider the central management system, which regulates physical recreation and sport activities at Iranian universities.

\section{International University Sport Federation (FISU)}

The main non-governmental organization which is responsible for sport at universities all around the world is the International University Sports Federation (FISU), which aims to promote sporting values and encourage sporting practice in harmony with, and complementary to, encouraging friendship, fraternity, fair-play, perseverance, integrity, co-operation and application amongst students who will one day hold responsible, and even key positions, in politics, the economy, culture and industry, which will give a new dimension to university spirit in terms of study, research, and discipline, through the strong affirmation of the full humanist development of the individual and, thus, formation of society at large" (Philosophy of FISU 2011).

FISU was founded in 1949 as the world governing body of national university sports organizations and currently has 153 member associations from five continental regions. Being the only international federation with more than fifty sports on its competition program, FISU stages its events every two years. They currently include two Universiades (summer and winter) and 32 World University championships. In addition, FISU permanently links the academic world with sports by hosting a number of educational events - conferences, forums and seminars. These events closely assist in promoting sport as one of the main components of the educational system (FISU History, 2011).

\section{Management of university sport in Iran}

\subsection{P.E. Department of Ministry of Science, Research and Technology of Iran}

The Physical Education Department of the Ministry of Science, Research and Technology of Iran is the central manager of sport at Iranian universities. It is responsible for running, making policy, planning, organizing, and supervising sports activities in universities that are covered by that ministry across the country. For achieving these objectives, three deputies are named: Design and Development Deputy, Technical Deputy and Women's Deputy. Some of the goals and missions of that department are:

- policy, planning and organizing sports activities, physical recreation and public sports in national universities,

- monitoring and evaluating progress and performance related to sport at the universities,

- decentralization in the implementation of national sports activities at the universities and transfer authority to the physical education offices at the universities,

- formation of and support for the sports forums within the universities, and to assist the development of public sport,

- planning, organizing, monitoring, and coordinating the different sport festivals, championships and Olympiads within and between the universities among the country,

- development of sport facilities and equipment to help encourage physical activity at the universities,

- development of local and traditional sport activities at the universities in each region,

- development of communication and scientific cooperation with domestic and international sport organizations (Central Department of Physical Education 2007).

\section{Deputy of Planning and Development}

A Planning and Development Deputy of the Physical Education Department, for planning and monitoring the performance of physical education and sport programs at the universities among the country, was created. The deputy promotes the sports facilities and equipment and scientific human 
resources, sport culture development, and reviews and provides strategies for optimizing general physical education credits at the universities, contributing to the development of sport at the universities.

The deputy is responsible for the review, monitoring and evaluation of the performance of physical education and sport programs at universities; planning and developing practical strategies for the maximum utilization of existing facilities, capabilities, and research for universities' sports requirements; forecasting and planning for the budget of the Central Department of Physical Education and presented to the Organization of Management And Planning of Iran; cooperating with the Iran Physical Education Organization and the Iran Management And Planning Organization in line with university sport; developing targeted and scheduled programs and sending them to universities for their implementation; the monitoring and conducting of programs; and improving public sports.

In addition, the development and promotion of knowledge, skills and sport culture among managers, physical education experts, sport specialists, and university students and consequently, the scientific movement through university sport life, are some of the other main tasks of this deputy. In this way, this deputy holds different classes and workshops in various research and teaching activity areas.

There are for units that are covered by this deputy: planning, monitoring and evaluation; development of university sport places; development of public sports; and education.

\section{Planning, Monitoring and Evaluation Unit}

This unit was formed with the aim of satisfying the development and policy objectives of the central physical education office in the form of short-term, intermediate, and long-term plans, and to identify the strengths and weakness in sport programs, and also to plan appropriate strategies in order to improve and reform any weaknesses.

\section{Development of university sport places}

The activities of this unit include the development, construction, and equipping of new - and reconstructing of unusable - sport places.

\section{Development of public sports}

This unit was formed with an aim to improve the happiness and exhilaration among students and staff at universities. Developing sport activities within the faculties and at students' residences and developing recreational sports at the universities are some of the duties of this unit.

\section{Education unit}

This unit assesses the interests and requirements of students, staff and managers of the universities related to sports, and encourage their knowledge through holding different workshops and classes at various levels.

\section{Technical Deputy}

This deputy is responsible for planning and supervising the hosting of different championships between universities all around the country and international competitions. The deputy actively supervises the coordination between sport forums at the universities and management of students' championships.

Some of the tasks related to this deputy include assisting in planning and implementing competition at national universities in cooperation with universities; events planning and implementation of provisions contained in the annual calendar; providing facilities for student sport teams for travel around the country; and the world student tournament championships. 


\section{Women's deputy}

Based on the importance of women's sport at Iranian universities, this deputy aims to encourage the motivation and participation of women in all fields of sport. Planning, implementation and monitoring women's sport activities, as a special form, are some part of the duties of this deputy, (Central Department of Physical Education 2007).

\section{Division of country into regions}

All of the universities around the country are divided into ten regions. The secretariat in each region is responsible for the monitoring and supervising of the operation of universities based on the main plans, on one hand, and the coordination between central departments of physical education and covered universities, on the other. The plan of dividing the universities around the country based on geographic regions, in line with the scientific principles and policies of the General Department of Physical Education, includes aims such as decentralization and increasing the effectiveness and efficiency of managers at different levels to achieve the predetermined goals of Sport Development Programs. Increasing the efficiency of existing sports facilities and equipment in each region, strengthening and developing the Volunteer Movement, attracting and employing experts in the regions, holding public sports festivals, and developing traditional and local sports related to the situation and location of each region are some of the plans and tasks of each region's secretariat around the country.

\section{Campaign volunteers}

The Central Physical Education Department is tasked with the aim of empowerment in partnership, encouraging students to hold sports activities, leisure enrichment for students and staffs, strengthening human resources efficiently, and the development of student participation in academic planning. It established the Volunteer Sports Association. In other words, the participation of students in the implementation of sport programs and sport events at the universities is centralized in this association (Central Department of Physical Education 2007). The Student Sport Association is an organization responsible for the coordination of the students' spontaneous activities and the encouragement of interested students in different sport activities and research. In addition, it aims to provide active leisure time and the enrichment of physical health and mental happiness in residences or faculties.

The establishment of the campus volunteers strengthens the human resources management of university sport by giving authority to the volunteers; the participation of students in decision making; planning applicable programs and running them in cooperation; and creating an environment filled with cooperation and assistance. Enhancing cooperation and partnership between students and universities could develop the relationship between them. (Aliabadi 2007).

\section{Sport participation of Iranian university students}

The sport activities related to university students can be divided into three categories: a) sport and recreational activities within universities, b) sport competitions between universities, c) Iranian students' participation in international competitions and Universiade.

\subsection{Sport and recreational activities within universities}

In consideration of the importance of physical activities for the all types of students with different abilities and skills, sport activities within universities are divided into sport and physical recreation and recreational sport competitions. During the entire academic year, there are many different recreational sport classes for the participation of students, where two parts for boys and girls 
are held and students can freely participate in those sports. Students who like to learn a new sport or develop their skills can participate in educational classes and those who like to participate separately can freely use the sport equipment.

The Public Sports Festival, which is held at Iranian universities, is another popular recreational activity. At this annual event, there are many types of public sports in which interested students can participate and enjoy. At the end of the festival, in order to improve the motivation of students and to encourage them to do sports and physical activities, top students are appreciated.

Additionally, many different programs are held at university residences. Those students who don't have time to participate in sport programs during the day can take part in these activities. Also, for the commemoration of Physical Education Week, many different games, matches and sport activities are held at both universities and residences.

One of the largest sports programs, held annually within Iranian universities, are the university Olympiads. This event has the aim of changing the lifestyle habits of students, emphasizing the role of physical education and exercise, improving personal and social lives, increasing the student population covered by mass sports activities, the orientation and enrichment of students, and promoting leisure and sports in general. It is held every year, and a large number of students participate in many types of sport competitions (Aliabadi 2007). At the opening ceremony, the aims of the event are read and in closing ceremony top athletes are appreciated.

\subsection{Sport competitions between universities}

Sport championships between universities are divided into four different events:

- university student championships across the region,

- $\quad$ university student championships across the country,

- university student public sports and recreational activity Olympiad across the country,

- $\quad$ university student sport Olympiad across the country.

\subsubsection{University student championships across a region}

These championships are regularly held every year; all university students can participate in these championships and compete with the other university students in the same region.

\subsubsection{University student championships across the country}

The university student championships across the country are staged every two years. These championships are staged over an extended period, in the form of a single sport. Each sport, due to variations in the facilities and situations of the universities, are held at different times of the year and at different universities. The top students across the regions can participate in these championships.

\subsubsection{University student public sports and recreational activity Olympiad across the country}

The Physical Education Department of the ministry, with regards to a policy of priority of developing public sports at the universities, has planned to hold a public sports and recreational activity Olympiad among all students at Iranian universities. The first Olympiads will be held this year.

\subsubsection{Universities Students' sport Olympiad across the country}

Based on the World Student competition (Universiade), the central department of Physical Education is to extend and expand sport among students, as well as develop the sense of commitment and responsibility to students in holding the tournament by attempting to organize Sport Olympiad for 
University Students across the country. The first Olympiad was held in 1992 at Tehran University (Olympiads History 2010). This Olympiad, held over the course of two weeks, consists of fourteen sports for men and seven sports for women, and is staged every two years and in two different parts for girls and boys separately in the middle of summer (Olympiads Calendars 2008). The protocol systems for the international student championship and this event are similar in that both events also share an opening and closing ceremony. All of the events are held at the Olympiads village, and the top students at these competitions can participate in the biggest international student championship (Universiade).

\subsection{Participation at the Universiade}

The Universiade is an international sporting and cultural festival, which is staged every two years in a different city and which is second in importance only to the Olympic Games. Governed by FISU, the aim of the Universiade is to promote international peace and cultural exchange among young people through sport (What is Universiade 2009). The first Universiade took place in 1923. The Federation International Sport Universities (FISU) was formed in 1948 (History of Universiade 2009). Numerous Olympic athletes have participated at Universiades. The events share much in common: the communal village, a mascot, and sporting conferences and cultural festivals that take place while the games are in progress. The protocol systems for the Olympics and Universiades are similar, with both events also sharing an opening and closing ceremony.

The summer Universiade consists of twelve compulsory sports, and each host is permitted to also choose a number of optional sports for the program (Summer Universiade 2009a). The Winter Universiade consists of seven compulsory sports and one or two optional sports also chosen by the host country (Winter Universiade 2011). Iranian student teams placed thirteenth in Universiade 2007 in Bangkok, and with five gold, two silver and one bronze medal, then moved up to rank eleventh in 2009 in Belgrade (Summer Universiade 2009b).

In the end, the aim of all of these events is increased student participation in athletic programs and more coverage of the population by sport exercise and experiencing the benefits of it. Additional aims include forming useful and active leisure time for the students and creating close and intimate relationships between students within Iran and other countries.

\section{Conclusion}

Physical education and sport at universities is an important part of the sport for society, playing an effective role in improving moral, mental and physical health, and also in developing the culture of sport in all strata of society.

The department of Physical Education of Iran's Ministry of Science, Research and Technology centrally manages sport affairs at Iranian universities, and as such, with regards to its policies and aims, actively and efficiently considers the development of student sport. The division of duties for organizing university sports to three deputies, as well as emphasizing women's sport, was a big step for developing student sport and expanding the participation of women into sport activities.

Decentralization is one of the most important policies of the department of PE of Iran's ministry. The division of the universities into ten geographical regions was an important measure in the development of sport in all the universities around the country. The allocation of more power to the secretariats to make decisions in each region, their receiving more authority for holding different sport programs and events, including the financial support of themes, might help to expand university sport.

In addition, the development of local and traditional sports in each region of the country could encourage a large number of students to participate in sport activities at universities. Holding local and traditional sports festivals not only in each region, but also at all universities around the country could 
introduce these types of sports and different cultures and customs to other students, and moreover, could stimulate an increase in the participation of students in these special events.

\section{REFERENCES}

Aliabadi, S. (2007). Development of sport in universal size. Retrieved from www.mardomsalari.com.

Central Department of Physical Education (2007). Retrieved from www.msrt.ir.

History of Universiade (2009). Australian University Sport. Retrieved from www.unisport.com.au.

FISU History (2011). Retrieved from www.fisu.net.

Bastani, H., Rad, H. Hosseini, A., Sairafi, H. (2006). Sport in ancient of Iran. The first international symposium of history of sport in Iran. Iranian Olympic and Paralympic National Academy. Tehran.

Khorami, Gh. (2009). An investigation on factors and barriers affecting the participation of the students from selected universities of Mashhad in public sports programs. MS Thesis, Payam E Noor University of Tehran.

National Iranian University Sport Federation (2011). Retrieved from www.iusf.ir.

Olympiads Calendars (2008). Calendar of holding the 9th Sport Olympiad. Retrieved from www.msrt.ir.

Olympiads History: A short history about students Olympiads across the country (2010) $10^{\text {th }}$ Students Sport Olympiad Across the country. Retrieved from http://olympiad10th.ir

Philosophy of FISU (2011). Retrieved from www.fisu.net.

Razi, M. (2007). History of Sport in Iran. The Roshd Journal, Retrieved from http://daneshnameh.roshd.ir.

Shajie, R., Dehghan, A., Javadian, N. (2007). Study on present situation. Challenges and perceived barriers forward to volunteers forums in Ferdosi Mashhad University. The fifth physical education and sport sciences student conference.

Summer Universiade (2009a). Australian University Sport. Retrieved from www.unisport.com.au.

Summer Universiade (2009b). Retrieved from www.en.wikipedia.org/wiki/2009_Summer_Universiade.

What is universiade (2009). Australian University Sport. Retrieved from www.unisport.com.au.

Winter Universiade (2011). Erzurum winter Universiade 2011. Retrieved from www.worldcurling.org.

AUTHOR'S ADDRESS: $\quad$ Hamidreza Mirsafian

Semmelweis University

Faculty of Sport and Physical Education Sciences (TF)

1123 Alkotás u. 44.

Budapest, Hungary

Email: Hamidmirsafian@gmail.com 